\title{
Cambio de uso del suelo en la cuenca del río Sabinal, Chiapas, México
}

\author{
Land-use change in the Sabinal river watershed, Chiapas, Mexico \\ Mercedes Concepción Gordillo-Ruiz ${ }^{1}$, Miguel Angel Castillo-Santiago ${ }^{2 *}$ \\ ${ }^{1}$ Coordinación Técnica de Investigación, Secretaría de Medio Ambiente e Historia Natural, Calzada de los Hombres llustres s/n, \\ CP. 29000,Tuxtla Gutiérrez, Chiapas, México. \\ ${ }^{2}$ Laboratorio de Análisis de Información Geográfica, El Colegio de la Frontera Sur, Carretera Panamericana y Periférico Sur s/n, \\ CP. 29290, San Cristóbal de las Casas, Chiapas, México. \\ *Autor de correspondencia: mcastill@ecosur.mx
}

Artículo científico recibido: 13 de mayo 2015, aceptado: 15 de enero de 2016

RESUMEN. Con el propósito de conocer que los factores promueven el cambio en la cobertura del suelo en la cuenca del río Sabinal, Chiapas, este trabajo analiza la relación entre mapas de cambio en la cobertura del suelo y estadísticas socioeconómicas. Se elaboraron mapas de la cobertura del suelo de 1992 y 2009 con imágenes satelitales de alta resolución; también se colectaron y analizaron datos socioeconómicos relacionados con el uso del suelo. La comparación de los mapas muestra que la tasa de deforestación es del $0.5 \%$, la cual es más baja que la reportada en otras zonas de bosque tropical seco; la población rural se ha mantenido a niveles similares de 1990, pero la población urbana creció más del doble. La superficie promedio de potreros por productor se ha duplicado, pero la de cultivos se mantiene similar a 1992, ya que los campesinos prefirieron sistemas de producción extensivos. Los terrenos agrícolas han disminuido en extensión y se han desplazado a zonas de mayor pendiente debido a la expansión de las áreas urbanas. Se encontró una alta dependencia de insumos de otras regiones del país, pero la producción de alimentos básicos en la cuenca se ha mantenido a niveles de 1991.

Palabras clave: Chiapas, cambio en la cobertura del suelo, urbanización, deforestación, migración rural

ABSTRACT. In order to know the factors that promote land-cover changes in the Sabinal River watershed, Chiapas, the relationship between land-cover change maps and socioeconomic statistics is analyzed in this paper. Land-cover maps of 1992 and 2009 were prepared using high-resolution satellite images; also, socioeconomic data regarding land use were collected and analyzed. Comparison of the maps shows that the deforestation rate in this area is $0.5 \%$, which is lower than that reported in other tropical dry forest areas; the rural population remained similar to 1990 levels, but the urban population more than doubled. The average pasture area per farmer has doubled, but the average crop area has remained virtually unchanged since the first study year, as farmers prefer extensive production systems. Due to the expansion of urban areas, agricultural lands have decreased in size and quality, since they have moved to hilly lands. High dependence on inputs from other regions was evident; staple food production in the watershed has remained at 1991 levels.

Key words: Chiapas, land-cover change, urbanization, deforestation, rural migration

\section{INTRODUCCIÓN}

El impacto de la población humana sobre los recursos naturales ha crecido a niveles sin precedentes (Haberl et al. 2014); el uso de la tierra para producir bienes y servicios representa la alteración humana más significativa de los ecosis- temas terrestres (Vitousek et al. 2009). La responsabilidad de la población en la modificación de los ecosistemas es incuestionable, pero la forma en la que las diferentes actividades del quehacer humano participan en la configuración del paisaje es poco conocida y representa un reto para los investigadores, debido a la complejidad de las relaciones 
entre la sociedad y el ambiente (Liu et al. 2007).

Con la disponibilidad de sensores remotos se ha podido medir con precisión la extensión y ubicación de los ecosistemas terrestres y los cambios que han sufrido en las últimas décadas (Hansen et al. 2013). Sin embargo entender el papel que desempeña la población humana en la configuración del ambiente biofísico, representa un reto (Turner et al. 2007). Desde la perspectiva de las disciplinas que abordan el estudio del cambio de uso del suelo con diferentes enfoques o escalas de trabajo, se han propuesto explicaciones que en ocasiones llegan a conclusiones divergentes (Wright y MullerLandau 2006, Sloan 2007). Para algunos autores la población que depende de las actividades económicas primarias es que ejerce mayor presión sobre los recursos forestales (Aide y Grau 2004, Wright y Muller-Landau 2006). Mientras que otros estudios proponen que estas aseveraciones corresponden a visiones parciales del problema, ya que no consideran que en ocasiones, cuando disminuye la densidad de población rural, ocurre un incremento en los sistemas agrícolas extensivos (Sloan 2007), por lo que no se toma en cuenta el creciente papel de factores exógenos que atenúan la influencia de los factores locales (Sloan 2007, Seto et al. 2012, Meyfroidt et al. 2013). En un análisis que incluye los casos de países tropicales, De Fries et al. (2010) indican que el crecimiento de la población urbana y la agricultura comercial de exportación, se encuentran correlacionados de forma positiva con la deforestación. La acelerada urbanización amenaza los recursos forestales (Pandey y Seto 2015).

En últimos años, México experimentó un acelerado cambio en la cobertura del suelo, con una estimación en la tasa de deforestación de los bosques tropicales de $0.76 \%$ de 1976 al 2000 (Mas et al. 2004). Para el caso del sureste de México, se reporta una disminución en las tasas de deforestación, que no necesariamente implican mayor conservación de los bosques (Kolb y Galicia 2012, Vaca et al. 2012), atribuyéndose este fenómeno a una incipiente transición forestal (Aide y Grau 2006). Adicional a estos esfuerzos por explicar los cambios de uso del suelo en la región, son pocos los estudios que exploran las causas de los cambios a escala local. Por lo anterior, el objetivo del presente trabajo fue conocer los factores que promueven los cambios en la cobertura y uso del suelo en la cuenca del río Sabinal, con base en las tendencias de los datos socioeconómicos y el análisis de los patrones de cambio en el uso del suelo.

\section{MATERIALES Y MÉTODOS}

\section{Área de estudio}

La cuenca del río Sabinal abarca una extensión de $407.4 \mathrm{~km}^{2}$, se localiza entre los $16^{\circ} 42^{\prime} \mathrm{y}$ $16^{\circ} 50.4^{\prime}$ de LN y los $93^{\circ} 03^{\prime}$ y $93^{\circ} 20^{\prime}$ de LO; entre los municipios de Tuxtla Gutiérrez, Chiapa de Corzo, San Fernando, Berriozábal y Ocozocuautla, en el estado de Chiapas, México. En su parte baja se localiza la ciudad de Tuxtla Gutiérrez, uno de los más grandes asentamientos humanos de la región y capital del estado (Figura 1). Su área de escurrimiento está delimitada por elevaciones de origen marino, formando un relieve abrupto, con una variación altitudinal de los 500 a los $1280 \mathrm{~m}$ en la porción noreste de la cuenca. El clima dominante es cálido húmedo, con subgrupos climáticos de cálido subhúmedo en el sur y cálido de humedad media en el norte. Presenta una importante diversidad edáfica conformada por seis unidades de suelo, distribuidos de forma irregular a lo largo del territorio, aunque con una notable dominancia de suelos de baja fertilidad como los litosoles, rendzinas en la laderas de las partes altas y vertisoles en las laderas de las partes bajas y el valle (SEMAVI 2009).

El río Sabinal es el principal escurrimiento superficial en la cuenca y único con caudal permanente durante todo el año; además de 15 arroyos de naturaleza intermitente. Los tipos de vegetación más importantes son el bosque tropical caducifolio y el bosque tropical subcaducifolio; con distribución reducida, fragmentos de bosque de encino y bosque de galería.

\section{Procesamiento de datos satelitales}

Se emplearon dos imágenes satelitales, una Landsat TM de 1992 y una Spot 5 del 2009. La 


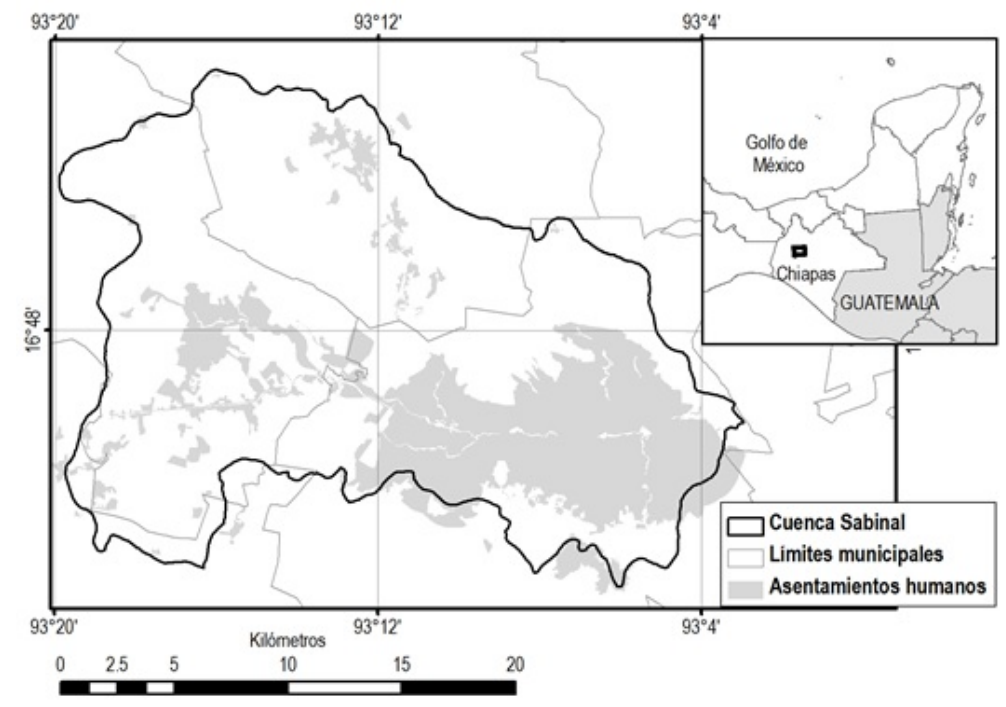

Figura 1. Localización de área de estudio.

imagen Landsat se descargó del portal del USGS, mientras que la imagen Spot se obtuvo del proyecto ERMEXs por un acuerdo de uso para centros de investigación. Las imágenes se corrigieron geométricamente con puntos de control tomados con GPS y referenciadas en el sistema de coordenadas UTM zona 15 con datum WGS84.

Para la elaboración de los mapas de cobertura del suelo, se empleó un proceso de fotointerpretación, delimitando los polígonos de forma directa en la pantalla. El trazado de los polígonos correspondientes a diferentes tipos de cobertura de suelo se realizó con base en criterios de tonalidad, textura, patrones espaciales de los rasgos de cada escena y comparación de imágenes de diferentes fechas. Se fotointerpretó primero la imagen más reciente, ya que tuvo mayor cantidad de información de apoyo, posteriormente los polígonos se sobrepusieron a la imagen de 1992, para delimitar las áreas que presentaron cambios en la cobertura del suelo.

Como material de apoyo para la fotointerpretación se utilizaron ortofotos tomadas en enero de 2001 escala 1:75 000 en blanco y negro, y una en marzo de 2007 escala 1:40 000 a color. También se emplearon datos satelitales de alta resolución de Google Earth y de campo. Los recorridos para la toma de datos de campo se realizaron de 2010 a 2012. En cada sitio visitado se recabó información descriptiva sobre el uso del suelo y tipos de vegetación, se registraron las coordenadas geográficas; y se entrevistaron a personas de la región para conocer los usos del suelo de años anteriores.

Se definieron siete clases generales para la interpretación de la cobertura del suelo las cuales se encuentran descritas en la Tabla 1. Los elementos lineales, como caminos de terracería, brechas con ancho menor a $10 \mathrm{~m}$ y los rasgos con dimensiones menores de 4 ha, no se tomaron en cuenta en el proceso de fotointerpretación.

Para detectar la magnitud y dirección de los cambios, los mapas se intersectaron de forma espacial con las funciones del SIG. Para finalmente obtener los mapas de cambios, que muestran donde ocurrieron y la matriz de cambios para resumir de forma cuantitativa las transformaciones ocurridas. También se calculó la tasa de deforestación con la ecuación propuesta por la FAO (1996):

$$
T D A=\left[1-\left(A_{2} / A_{1}\right)^{1 / n}\right] * 100
$$

Donde: $\mathrm{A}_{1}=$ área al inicio del periodo, $\mathrm{A}_{2}=$ área al 
Tabla 1. Clases utilizadas en el mapeo de la cobertura forestal y usos del suelo.

\begin{tabular}{|c|c|}
\hline Cobertura del suelo & Descripción \\
\hline Bosques & $\begin{array}{l}\text { Áreas que presentan vegetación leñosa con altura superior a cinco metros y cubierta de dosel superior al } \\
10 \% \text {. Incluye la vegetación arbórea con diámetro mayor a } 10 \mathrm{~cm} \text { y que por sus características fisonómicas } \\
\text { pertenecen a los siguientes tipos: bosque tropical caducifolio, bosque tropical subcaducifolio, bosque de } \\
\text { encino y bosque de galería. }\end{array}$ \\
\hline Vegetación secundaria & $\begin{array}{l}\text { Vegetación que se desarrolla después de que el bosque original ha sido eliminado por efecto de una per- } \\
\text { turbación. En la mayoría de los casos resultan de terrenos de uso agrícola y pecuario que se encuentran } \\
\text { en etapa de recuperación. }\end{array}$ \\
\hline Cultivos & Áreas con cultivos agrícolas y pastizales para agostadero. \\
\hline Suelo desnudo & $\begin{array}{l}\text { Áreas desprovistas de vegetación debido a las actividades de minería a cielo abierto, extracción de caliza } \\
\text { para la producción de cal, principalmente. }\end{array}$ \\
\hline Cuerpo de & Ríos con un flujo permanente de agua. \\
\hline Asentamientos humanos & $\begin{array}{l}\text { Áreas dedicadas a la vivienda, zonas comerciales e incluye obras e infraestructura urbana, instalaciones y } \\
\text { vías mayores de comunicación como, pista área y líneas de transmisión eléctrica. }\end{array}$ \\
\hline Caminos & Vías de comunicación que considera las carreteras pavimentadas de un solo carril. \\
\hline
\end{tabular}

final del periodo y $\mathrm{N}=$ número de años del periodo.

\section{Datos socioeconómicos}

Se acopiaron datos del Instituto Nacional de Estadística y Geografía (INEGI), correspondientes a los censos de población y vivienda de 1990 y 2010, además de los censos agrícolas y ganaderos de 1991 y 2007. También se aplicaron 136 encuestas a campesinos de los seis ejidos representativos de la cuenca. En cada localidad se entrevistó entre $10 \mathrm{y}$ $15 \%$ del patrón de ejidatarios, seleccionados por la técnica de bola de nieve (Martin-Crespo y Salamanca 2007), comenzando con los representantes ejidales. La encuesta se centró en la historia del uso del suelo y las actividades económicas actuales de las parcelas. Para obtener la información histórica, se preguntó al entrevistado los usos de la tierra que recordaba desde que la compró o heredó. La información proporcionada por los campesinos sobre tendencias en la productividad, se complementó con los censos agrícolas y ganaderos del INEGI y con datos del Sistema de Información Agroalimentaria y Pesquera (SIAP).

\section{RESULTADOS}

\section{Cambios en la cobertura del suelo}

De 1992 a 2009, el área de estudio presentó cambios importantes en su estructura espacial. En general el $72 \%$ del territorio de la cuenca conservó su mismo tipo de cobertura de suelo, mientras que
$28 \%$ tuvo algún tipo de cambio (Tabla 2). Con la sobreposición de los mapas mapas se observó que los bosques sufrieron un decremento de 663 ha, lo que representa $8.7 \%$ de la superficie original y corresponde a una tasa de deforestación del $0.5 \%$; la vegetación secundaria disminuyó en 177 ha, lo que representa $1.5 \%$ de la extensión original. Los mayores cambios ocurrieron en las coberturas del suelo dedicadas a los asentamientos humanos y cultivos. El área de cultivos tuvo una disminución de 3538 ha, lo que representa $24.2 \%$ del área original de 1992; mientras que los asentamientos humanos se expandieron en 4331 ha, lo que equivale a un crecimiento del $63 \%$. Mientras que los suelos desnudos aumentaron en 42 ha, que en términos relativos implicó un crecimiento del $70 \%$. Las principales transiciones entre los tipos de cobertura del suelo se pueden observar en la Tabla 3. Las transiciones entre los bosques y la vegetación secundaria son similares, con una ligera tendencia a perder bosques, más que a ganarlos vía regeneración. Se observó un flujo significativo, ocurrido entre el área cultivada y la vegetación secundaria, ya que $20 \%$ de las tierras de cultivo abandonadas se regeneraron y $12.2 \%$ de la vegetación secundaria se incorporó de nuevo a la producción agropecuaria.

Los asentamientos humanos fueron el tipo de cobertura receptora de la mayoría de las áreas transformadas, $37.4 \%$ de los cambios se debieron a la conversión de zonas de cultivos y vegetación secundaria, en uso de asentamientos humanos. 
Gordillo-Ruiz et al.

Tabla 2. Superficies ocupadas por los tipos de cobertura y usos del suelo en la cuenca río Sabinal.

\begin{tabular}{|c|c|c|c|c|c|c|}
\hline \multirow{2}{*}{ Clases } & \multicolumn{2}{|c|}{1992} & \multicolumn{2}{|c|}{2009} & \multirow{2}{*}{$\begin{array}{c}\text { Cambio en superficie } \\
\text { ha }\end{array}$} & \multirow{2}{*}{$\begin{array}{c}\text { Cambio con respecto } \\
\text { a la superficie inicial } \\
(\%)\end{array}$} \\
\hline & ha & $(\%)$ & ha & $(\%)$ & & \\
\hline Bosques & 7566 & 18.6 & 6903 & 16.9 & -633 & -8.3 \\
\hline Vegetación secundaria & 11505 & 28.2 & 11328 & 27.8 & -177 & -1.5 \\
\hline Cultivos & 14618 & 35.9 & 11081 & 27.2 & -3537 & -24.2 \\
\hline Asentamientos humanos & 6874 & 16.9 & 11205 & 27.5 & 4331 & 63.0 \\
\hline Cuerpos de agua & 5 & 0.0 & 5 & 0.0 & 0 & 0 \\
\hline Suelo desnudo & 60 & 0.1 & 102 & 0.3 & 42 & 70.0 \\
\hline Caminos & 117 & 0.3 & 121 & 0.3 & 4 & 3.4 \\
\hline
\end{tabular}

Tabla 3. Matriz de cambios de la cobertura del suelo en la cuenca río Sabinal en hectareas.

\begin{tabular}{|c|c|c|c|c|c|c|}
\hline & \multirow[b]{2}{*}{ Clases } & \multicolumn{5}{|c|}{1992} \\
\hline & & Bosques & $\begin{array}{l}\text { Vegetación } \\
\text { secundaria }\end{array}$ & Cultivos & $\begin{array}{r}\text { Asentamientos } \\
\text { humanos }\end{array}$ & Subtotal \\
\hline \multirow{5}{*}{ ஓे } & Bosques & 5,558 & 1,033 & 284 & 24 & 6,899 \\
\hline & Vegetación secundaria & 1,590 & 7,482 & 2,219 & 29 & 11,320 \\
\hline & Agropecuario & 181 & 1,363 & 9,483 & 21 & 11,049 \\
\hline & Asentamientos humanos & 222 & 1,581 & 2,599 & 6,800 & 11,202 \\
\hline & Subtotal & 7,551 & 11,460 & 14,586 & 6,874 & 40,471 \\
\hline
\end{tabular}

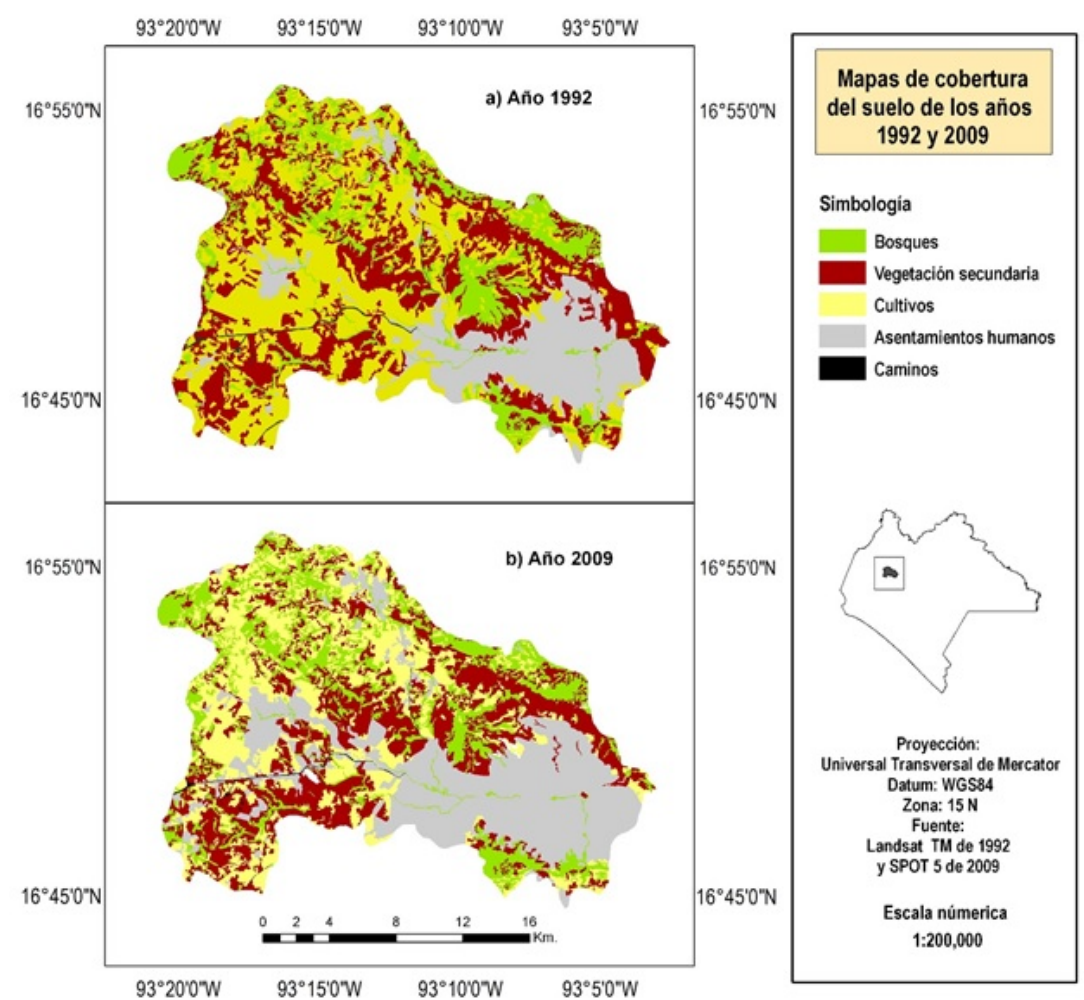

Figura 2. Mapa de los principales cambios de la cobertura del suelo ocurridos. 
Este proceso es más evidente en los municipios de Berriozábal y Tuxtla Gutiérrez (Figura 2). Los asentamientos humanos han ocupado los terrenos más adecuados para la producción agrícola; ya que $69.3 \%$ de los cambios de cultivos a zona urbana han ocurrido en terrenos con poca inclinación, con pendientes menores del $10 \%$, mientras que 29.2 $\%$ de los terrenos tienen inclinación moderada con pendientes entre 10 y $30 \%$, en tanto que $1 \%$ de los terrenos tienen pendientes fuertes (> $30 \%$ ).

\section{Dinámica demográfica}

El crecimiento demográfico en los municipios la cuenca, se concentra principalmente en Tuxtla Gutiérrez, mientras que la población en las zonas rurales tiene un ligero crecimiento. En el período de 1990 a 2010 la población de Tuxtla pasó de 313 790 a 585795 habitantes, mientras que la población rural aumentó de 10185 a 13931 habitantes. En las últimas décadas la capital del estado registró migración inferior a la cifra promedio estatal. Lo que significa que el crecimiento observado se debe, al crecimiento natural de la población y a la migración interna del campo a la ciudad. Este crecimiento en las áreas urbanas, ha implicado disminución de la población dedicada a las actividades primarias e incremento de la población dedicada a las actividades secundarias.

\section{Sistemas de producción agrícola}

El $95 \%$ de los campesinos entrevistados son originarios del área de estudio, el resto provienen de otras partes del estado, de ellos $75 \%$ sabe leer y escribir, $25 \%$ concluyó la educación primaria y $8 \%$ tiene estudios superiores al nivel básico. La agricultura es la principal actividad productiva a la que se dedican, le siguen en orden de importancia la combinación de actividades agrícolas y ganaderas. En tanto que $21 \%$ desempeñan actividades del campo y servicios (Figura 3 ).

Los productores dedicados a cultivar la tierra distribuyen su tiempo en el cultivo de maíz, frijol, café y frutales. El cultivo del maíz generalmente se asocia con el cultivo del frijol y la calabaza. Otros cultivos de importancia son el café, el chayote y los frutales como el limón, plátano y naranja. La superficie de labor empleada por productor para siembra no ha cambiado, ya que en promedio siembra tres hectáreas (Tabla 4). Desde la década de los ochenta se usan agroquímicos, pero esto no ha resultado en una mejora de rendimiento agrícola, en el caso del maíz y fríjol los rendimientos son de $1.5 \mathrm{t} \mathrm{ha}^{-1}$; debido a que las áreas de cultivo se encuentran en terrenos con pendientes y menor aptitud agricultura. El $52 \%$ de los productores reciben apoyo del Programa de Apoyo Directo al Campo (PRO(AMPO), para el cultivo de maíz de temporal y pastos perennes, y $28 \%$ recibe subsidio del Programa Producción Pecuaria Sustentable y Ordenamiento Ganadero y Apícola (PROGAN). La ganadería es una actividad que ha retomado fuerza, al inicio del periodo de evaluación se empleaban en promedio 7.5 has para la ganadería por productor, la cual ha incrementado al doble (Tabla 4). Todos los encuestados en el municipio de San Fernando han cambiado sus terrenos agrícolas y forestales al uso pecuario.

El sistema para la producción de ganado bovino es extensivo, los pastizales se emplean para el pastoreo en las zonas con fragmentos de bosque, cañadas, acahuales y pequeñas áreas de cultivos de maíz; ya que son potreros que soportan una baja carga animal (Tabla 4). En Berriozábal el propósito es la cría en pie y en San Fernando doble propósito. La producción se destina al mercado local. Los becerros y toretes son vendidos para engorda, y las vacas de desecho se comercializan en los rastros de los ayuntamientos o con intermediarios. La leche y otros derivados lácteos se vende en las queserías particulares de las cabeceras municipales y en los ejidos vecinos.

\section{DISCUSIÓN}

La cuenca del Sabinal presenta una dinámica socioeconómica y de cambios en el uso del suelo, similar al de otras regiones con economías de libre mercado en países en desarrollo, ya que tiene una fuerte migración de la población rural a los centros 


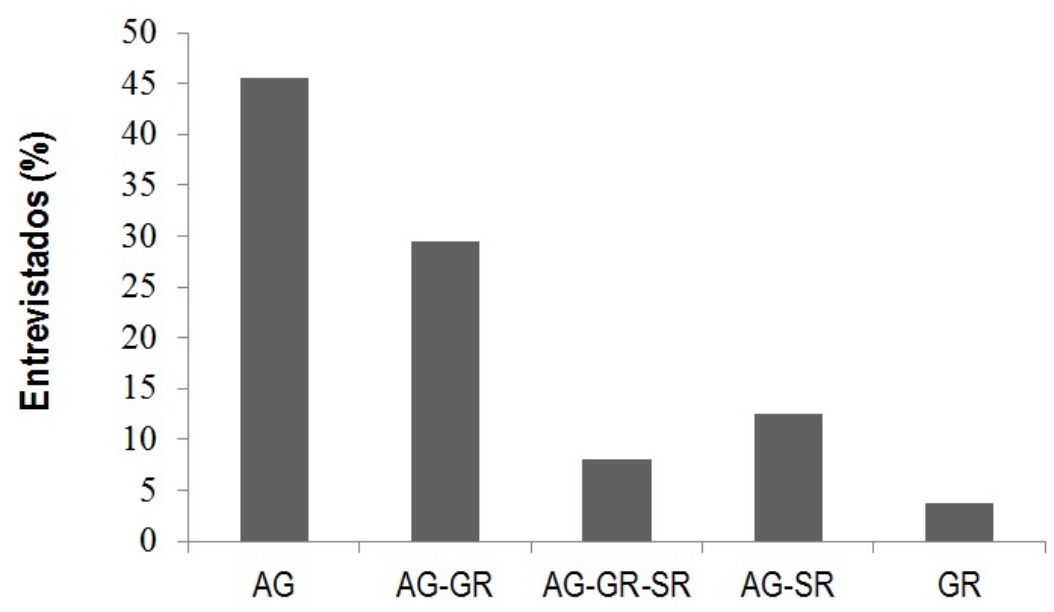

Figura 3. Actividades económicas actuales en las comunidades de estudio, $A G=$ Agricultura, $G R=$ Ganadería y $S R=$ Servicios.

Tabla 4. Matriz de cambios de la cobertura del suelo en la cuenca río Sabinal de 1992 al 2009.

\begin{tabular}{lrrr}
\hline & Actividad económica & Intervalo & Mediana Promedio \\
\hline Superficie Agrícola* (ha): & & 2 & 3.28 \\
Antes & $1-21$ & 2 & 3.76 \\
Ahora & $1-40$ & & \\
Superficie destinada a los potreros (ha) & & 3 & 7.5 \\
Antes & $1-52$ & 11 & 15.02 \\
Ahora & $1-80$ & 14 & 12 \\
Número de cabezas de ganado (actual) & $1-96$ & 0.41 & 0.51 \\
Número de cabezas/hectárea (actual) & $0-3.2$ & 4 & 10.42 \\
Superficie actual total de la propiedad (ha) & $1-100$ &
\end{tabular}

urbanos, pérdida del capital humano y acelerado crecimiento urbano (De Fries et al. 2010, Delgadillo y Torres 2009). Este enfoque de desarrollo ha traído cambios en el medio rural y urbano, influyendo en general en la configuración del territorio y en los procesos de cambio de los uso de suelo de la cuenca (Ortega et al. 2010, Torres 2011).

Los procesos de cambio de uso del suelo más importantes en la cuenca han sido el de bosque por terrenos agrícolas y la expansión de la mancha urbana en zonas de vegetación secundaria y cultivos. La pérdida del bosque es de menor intensidad que en otras partes del estado, la tasa de deforestación reportada para los bosques tropicales secos del sureste de México en el período de 1993 a 2007 es de 2.24 $\%$ (Kolb y Galicia 2011), mientras que en la cuenca Sabinal es de $0.5 \%$. En la cuenca de San Cristóbal, una región densamente poblada y colindante al Sabinal, también se observó un decremento en la tasa de deforestación anual de $0.19 \%$ desde 1975 a 2009; en este caso el fenómeno ha sido atribuido a una combinación de factores que incluyen la migración y alternancia de los tiempos entre la agricultura y prestación de servicios en la zona urbana (FigueroaJáuregui et al. 2011). Aun cuando el bajo nivel de deforestación puede tomarse como un dato positivo, para una región que ha experimentado un alto crecimiento poblacional, pequeñas pérdidas de la cobertura arbórea y el avance de la mancha urbana han implicado incrementos en la vulnerabilidad de la población (SEMAVI 2009). En 1993 y 2003 la cuenca sufrió fuertes inundaciones, lo cual se pudo deber a la disminución de la superficie de infiltración (SMPC 2013). 
El crecimiento de los asentamientos humanos es el proceso dominante en la cuenca, durante el período de estudio más de 4000 ha han sido convertidas a este tipo de uso, debido al crecimiento de la población urbana y la inmigración rural, por su condición geopolítica como capital del estado, en donde se concentran la mayor parte de las actividades económicas, educativas y de servicios. El proceso de urbanización acelerada de la cuenca es un patrón observado a nivel mundial, especialmente en Latinoamérica y el Sureste de Asia (García-Orozco et al. 2012, Seto et al. 2012, Meyfroidt et al. 2013). Otro fenómeno, observado es la transformación del paisaje rural a uno de zonas periurbanas, debido en parte al poblamiento e instalación de locales comerciales en las inmediaciones de las vías de comunicación que conectan a la ciudad de Tuxtla Gutíerrez con ciudades vecinas; procesos similares de pérdida de los ambientes rurales son comunes en las inmediaciones de las grandes centros urbanos (Juan-Pérez 2013).

El aumento de la población de Tuxtla Gutiérrez, no ejerce una mayor demanda de los productos agrícolas dentro de la región, ya que la producción agropecuaria en los municipios de la cuenca se mantiene en niveles similarares de hace 17 años e incluso en algunos casos disminuyó (Figura 4). Esta tendencia se confirma con los mapas, donde se observa que la superficie destinada al uso agropecuario disminuyó de forma significativa, ya que $24 \%$ de la extensión original ha sido remplazada por uso urbano. De acuerdo a estos indicadores, los productos agropecuarios necesarios para alimentar a la población urbana de la cuenca, provienen de fuera, lo que es resultado de la evolución en el patrón de abastecimiento de los alimentos inducida por el modelo de desarrollo económico, donde la ciudad de Tuxtla Gutiérrez, es el eje. Al respecto Torres (2011) ubica a este patrón como el nuevo modelo de abastecimiento en las zonas densamente pobladas de México, donde la dimensión espacial del patrón se encuentra modelado por las metrópolis.

La dinámica observada entre las áreas de cultivos y la vegetación secundaria se explica por el sistema de producción agrícola de roza, tumba y quema. Ya que se practica en suelos frágiles que con el uso continuo disminuyen su productividad. De acuerdo con los entrevistados, antes era frecuente tener hasta dos cosechas por año, pero ahora es una cosecha. Ya que la mayoría de ellos no disponen del capital necesario para mejorar la rentabilidad de sus terrenos ni tienen acceso a subsidios. Esto ha obligado a los campesinos a suspender las prácticas agrícolas en las parcelas, para permitir que se recupere la fertilidad del suelo por medio de un proceso de sucesión secundaria. Al respecto, Medina et al. (2005) reporta para el municipio de San Fernando baja rentabilidad de sus productos agropecuarios desde la década de los ochenta, por causas de suelos erosionados, sequías y problemas fitosanitarios. Así como, el abandono parcial del campo, debido a los bajos precios en los productos agrícolas y por la demanda de mano de obra en la ciudad de Tuxtla Gutiérrez.

Los cambios en los suelos desnudos, de 60 a 102 ha se deben al incremento en la actividad de la minería para producir calhidra, aunque no son significativos en términos absolutos, si lo son en términos del crecimiento relativo (70\%). Este tipo de cambios sugiere que no todas las transiciones pueden explicarse por la magnitud de la superficie afectada, ya que el impacto ambiental de las actividades mineras es mucho mayor que otros tipos. Los patrones de cambio observados en la región, como la acelerada urbanización, alta migración rural y bajas tasas de deforestación; confirman lo que algunos autores consideran como indicios de una transición forestal (Aide y Grau 2004, Vaca et al. 2012). Sin embargo, otros resultados indican lo contrario, por ejemplo la regeneración observada corresponde en mayor medida a una etapa de descanso del sistema rosa, tumba y quema, más que a un abandono absoluto de las tierras. El incremento en el uso extensivo de las tierras y la disminución en la producción de cultivos básicos, son evidencias que contradicen la posible transición forestal debido a la migración rural; en este caso los procesos observados son el resultado de relaciones complejas, que deben tomarse en cuenta, como los factores exógenos relacionados con la oferta y la demanda que conectan áreas dis- 


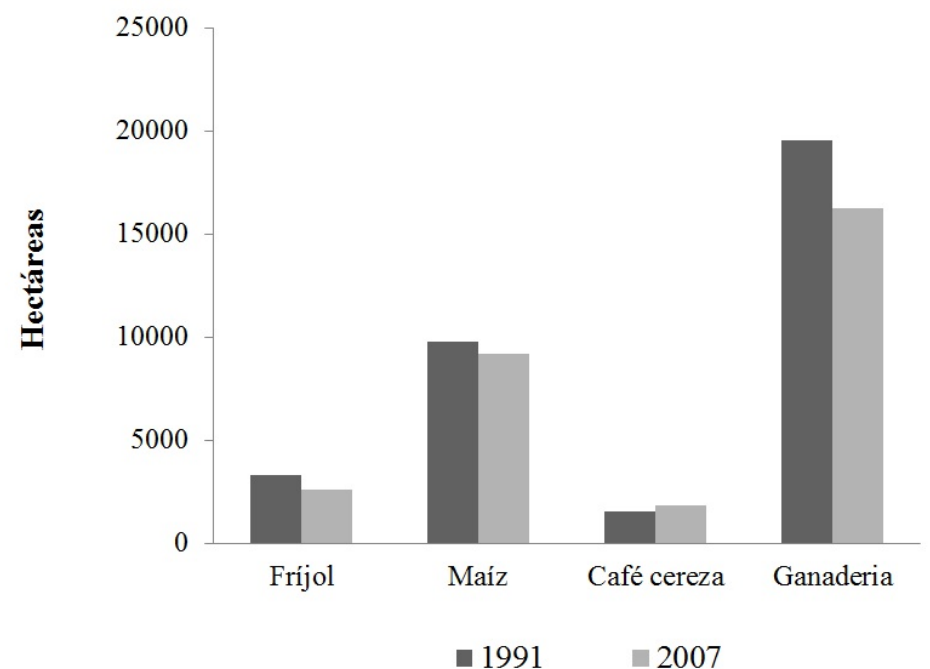

Figura 4. Comportamiento de los principales productos de la actividad primaria de acuerdo a los censos agropecuarios de 1991 y 2007, para los municipios de Berriozábal, San Fernando y Tuxtla Gutiérrez.

tantes para la producción de alimentos (Seto et al. 2012, Meyfroidt et al. 2013).

Los enfoques de modelación espacial del cambio de uso del suelo, toman en cuenta de forma explícita los factores que se expresan de forma física dentro de la región. Sin embargo, para comprender la complejidad de los procesos relacionados con el cambio de uso del suelo, es necesario considerar el papel de los mercados globalizados y la teleconexión entre regiones (Seto et al. 2012, Müller y Munroe 2014).

\section{CONCLUSIONES}

El $72 \%$ del territorio de la cuenca tiene el mismo tipo de cobertura de suelo, mientras que 28 $\%$ tuvo algún tipo de cambio. La migración rural y el crecimiento de la población urbana tienen poco relación con la deforestación y el comportamiento de la producción agrícola. El incremento urbano ha afecta de manera notoria las áreas dedicadas a actividades agrícolas, ya que ocupa las mejores tierras de cultivo. A pesar de ser una cuenca con baja tasa de deforestación, parece poco probable esperar una posible recuperación de los bosques, debido al crecimiento de prácticas agropecuarias extensivas.

\section{AGRADECIMIENTOS}

Al Fondo Mixto CONACYT-Gobierno del Estado de Chiapas y al Fondo Sectorial CONACYTINEGI por el financiamiento a los proyectos "Estrategias para la restauración y rehabilitación de la cuenca del rio Sabinal (Chis-2008-08-107668)" y "Análisis espacio-temporal de la vulnerabilidad del paisaje utilizando percepción remota y métodos espaciales (210080)"; a la Ing. Rosa Elena Flores Escobar por su apoyo en el trabajo de campo; y a los revisores anónimos por sus valiosos comentarios al manuscrito.

\section{LITERATURA CITADA}

Aide TM, Grau RH (2004) Globalization, migration and Latin American Ecosytems. Science 305: 1915-1916.

DeFries RS, Rudel T, Uriarte M, Hansen M (2010) Deforestation driven by urban population growth and agricultural trade in the twenty-first century. Nature Geoscience 3: $178-181$. 
Delgadillo MJ, Torres TF (2009) La gestión territorial como instrumento para el desarrollo rural. Revista Estudios Agrarios 15:55-73.

Figueroa-Jáuregui ML, Ibánez-Castillo LA, Arteaga-Ramírez R, Arellano-Monterrosas JL, Vázquez-Peña M (2011) Cambio de uso del suelo en la cuenca de San Cristóbal de las Casas, México. Agrociencia 45: 531-544.

FAO (1996) Forest resources assessment 1990 - survey of tropical cover and study of change processes. Organización de las Naciones Unidas para la Alimentación y la Agricultura. Roma, Italia. http://www.fao.org/ docrep/007/w0015e/w0015e00.htm. Fecha de consulta 23 de octubre de 2013.

García-Orozco JA, Cedillo-Gutiérrez JG, Juan-Pérez JI, Balderas-Platas MA (2012) Procesos de cambio en el uso del suelo de una microcuenca en el altiplano mexicano: el caso del río San José en el Estado de México. Papeles de Geografía 55-56: 63-73.

Haberl H, Erb KH, Krausmann F (2014) Human appropriation of net primary production: patterns, trends, and planetary boundaries. Annual Review of Environment and Resources 39: 363-391.

Hansen MC, Potapov PV, Moore R, Hancher M, Turubanova SA, Tyukavina A, et al. (2013) High-resolution global maps of 21st-Century forest cover change. Science 342:850-853.

INEGI (1991) VII Censo agrícola-ganadero. Instituto Nacional de Estadística, Geografía e Informática. Aguascalientes, México. http://www.inegi.org.mx/est/contenidos/proyectos/accesomicrodatos/cag1991/. Fecha de consulta 23 de octubre de 2014.

INEGI (1990) XII Censo general de población y vivienda. Instituto Nacional de Estadística, Geografía e Informática. Aguascalientes, México.http://www.inegi.org.mx/est/contenidos/proyectos/ccpv/cpv1990/. Fecha de consulta 14 de octubre de 2014.

INEGI (2010) XI Censo general de población y vivienda. Instituto Nacional de Estadística, Geografía e Informática. Aguascalientes, México. http://www.inegi.org.mx/est/contenidos/proyectos/ccpv/cpv2000/. Fecha de consulta 08 de abril de 2014.

INEGI (2007) VIII Censo agrícola-ganadero. Instituto Nacional de Estadística, Geografía e Informática, México. Aguascalientes, México. http://www3.inegi.org.mx/sistemas/tabuladosbasicos/. Fecha de consulta 21 de octubre de 2015.

Juan Pérez JI (2013) Análisis del cambio de uso del suelo en una región del altiplano mexicano, retos e impactos: 1986 - 2011. OIDLES 7(13) http://www.eumed.net/rev/oidles/13/cambio-uso-suelo.html: Fecha de consulta 20 Octubre 2015.

Kolb M, Galicia L (2012) Challenging the linear forestation narrative in the Neo-tropic: regional patterns and processes of deforestation and regeneration in southern Mexico. The Geographical Journal 178: 147-161.

Liu J, Dietz T, Carpenter SR, Alberti M, Folke C, Moran E, et al. (2007) Complexity of coupled human and natural systems. Science 317: 1513-1516.

Martín-Crespo BMC, Salamanca CB (2007) El muestreo en la investigación cualitativa. Nure Investigación 27: $1-4$.

Mas JF, Velázquez A, Díaz-Gallegos JR, Mayorga-Saucedo R, Alcántara C, Bocco G, et al. (2004) Assessing land use/cover changes: a nationwide multidate spatial database for Mexico. International Journal of Applied Earth Observation and Geoinformation 5: 249-261. 
Medina SL, Anaya GM, Volke HV, Ortiz CS (2005) Formulación de un plan de desarrollo agropecuario y forestal para una comunidad ejidal del municipio de San Fernando, Chiapas, México. Mundo Agrario 5: 1374-1405.

Meyfroidt P, Lambin E F, Erb KH, Hertel TW (2013) Globalization of land use: distant drivers of land change and geographic displacement of land use. Current Opinion in Environmental Sustainability 5: 438-444.

Müller D, Munroe DK (2014) Current and future challenges in land-use science. Journal of Land Use Science 9: $133-142$.

Ortega HA, León AM, Ramírez BV (2010) Agricultura y crisis en México: treinta años de políticas económicas neoliberales. Ra Ximhai 6: 323-337.

Pandey B, Seto KC (2015) Urbanization and agricultural land loss in India: Comparing satellite estimates with census data. Journal of Environmental Management 148: 53-66.

SMPC (2013) Atlas de riesgos del municipio de Tuxtla Gutiérrez. Gobierno Municipal. Chiapas, México. http://www.proteccioncivil.tuxtla.gob.mx/pg/pcivil/archivos/Atlas_de_riesgos_TGZ.pdf. Fecha de consulta 07 de junio de 2016.

SEMAVI (2009) Programa de Ordenamiento Ecológico de la Cuenca Río Sabinal. Secretaria de Medio Ambiente y Vivienda. Chiapas, México. http://www.bitacora.semahn.chiapas.gob.mx/oet/Oet2. Fecha de consulta 19 de septiembre de 2014.

SAGARPA (2015) Listado de beneficiarios. Secretaria de Agricultura, Ganadería, Desarrollo rural, Pesca y Alimentacion.http://www.sagarpa.gob.mx/agricultura/Programas/proagro/procampo/Beneficiarios/. Distrito Federal, México. Fecha de consulta 22 de octubre de 2014.

Seto KC, Reenberg A, Boone C, Fragkias M, Haase D, Langanke T, et al. (2012) Urban land teleconnections and sustainability. Proceeding of the National Academy of Sciences 109: 7687-7692.

SIAP (2015) Servicio de Información Agroalimentaria y Pesquera. http://www.siap.gob.mx/produccionagropecuaria/. Fecha de consulta 21 de octubre de 2015.

Sloan S (2007) Fewer people may not mean more forest for Latin American forest frontiers. Biotropica 39: 443-446.

Torres TF (2011) El abasto de alimentos en México hacia una transición económica y territorial. Problemas de Desarrollo 166: 63-84.

Turner II BL, Lambin EF, Reenberg (2007) The emergence of land change science for global environmental change and sustainability. Proceedings of the National Academy of Sciences 104: 20666-20671.

Vaca RA, Golicher DJ, Cayuela L, Hewson J, Steininger M (2012) Evidence of incipient forest transition in Southern Mexico. PLOS ONE 7: e42309.

Vitousek PM, Mooney HA, Lubchenco J, Melillo JM (1997) Human domination of Earth's ecosystems. Science 227: 494-499.

Wright JS, Muller-Landau HC (2006) The future of tropical forest species. Biotropica 38: 287-301 
